Maciej Fingas"

\title{
The Right to Interpretation and Translation in \\ Criminal Proceedings - \\ Challenges and Difficulties Stemming from the Implementation of the Directive 2010/64/EU
}

\section{Abstract}

In modern Europe issues related to the obligation to ensure the right to fair criminal trial for persons who do not speak or understand the language of the criminal proceedings are still pressing. The article discusses main problems stemming from the implementation of Directive 2010/64/EU, especially issues connected with: the scope of and exceptions to the right to written translation of essential documents, the problem of translation of all procedural applications submitted by the accused himself in a language other than the language of the court, the obligation to make available interpretation during communication between the accused and his legal counsel under confidentiality conditions, and - last but not least - professional qualifications of interpreters and translators providing assistance in criminal cases. The article points out that the glaring discrepancies among Member States in the legal and practical implementation of the right to interpretation and translation may result in divergent procedural standard in individual cases, depending on the location of the criminal proceedings.

\section{Introduction}

Directive 2010/64/EU is the first measure adopted within the framework of the Council's "Roadmap for strengthening procedural rights of suspected or accused persons in criminal proceedings" 1 . Although it is certainly hard to overestimate its significance for introducing common procedural rights, its provisions raise a number of doubts as to the practical consequences of the implementation of the Directive in the Member States. Therefore, this article discusses especially issues connected with: the scope of and exceptions to the right to written translation of essential documents, the problem

* The author is a postdoctoral researcher at the University of Gdansk, Poland.

1 As to the genesis of the Directive 2010/64/EU see: S. Cras, L. De Matteis, The Directive on the Right to Interpretation and Translation in Criminal Proceedings, The European Criminal Law Associations Forum 2010, vol. 4, p. 153-157.

DOI: $10.5771 / 2193-5505-2019-2-175$ 
of translation of all procedural applications submitted by the accused in a language other than the language of the court, the obligation to make available interpretation during communication between the accused and his legal counsel under confidentiality conditions, and the quality of interpretation and translation provided under Directive 2010/64/EU.

Obviously, a certain fair trial standard as to the assistance of an interpreter in criminal proceedings is a long-established one and follows from the European Convention for the Protection of Human Rights and Fundamental Freedoms (hereinafter the ECHR) and the case-law of the Strasbourg Court (hereinafter the ECtHR, the Court), which allows to identify several basic elements thereof. It is important in the light of recital 32 of the Directive, which provides: "The level of protection should never fall below the standards provided by the ECHR or the Charter as interpreted in the caselaw of the European Court of Human Rights or the Court of Justice of the European Union".

Paragraph 3 (a, e) of Article 6 of the ECHR guarantees that everyone charged with a criminal offence has the right to be informed promptly, in a language which he understands and in detail, of the nature and cause of the accusation against him and to have the free assistance of an interpreter if he cannot understand or speak the language used in court. In Luedicke, Belkacem and Koç ECtHR noted that an interpreter's assistance must be free, without the costs incurred subsequently claimed back from the accused ${ }^{2}$, regardless of the criminal court's final decision in the matter of guilt. As the Court aptly pointed out, the obligation for a convicted person to pay interpretation costs may have repercussions on the exercise of his right to a fair trial, because in some borderline cases the appointment or not of an interpreter might depend on the attitude taken by the accused, which might in turn be influenced by the fear of financial consequences ${ }^{3}$. It was also clearly indicated in abovementioned judgment that an accused who cannot understand or speak the language used in court has the right to the free assistance of an interpreter for the translation or interpretation of all those documents or statements in the proceedings instituted against him which it is necessary for him to understand in order to have the benefit of a fair trial ${ }^{4}$. On several occasions, the Court noted, however, that paragraph 3 (e) does not go so far as to require a written translation of all items of written evidence or official documents in the procedure. Therefore, it was pointed out that oral linguistic assistance may satisfy the requirements of the Convention if only interpretation assistance provided is such as to enable the defendant to have knowledge of the case against him and to defend himself, notably by being able to put before the court his version of facts. However, it is the way in which the accused is informed of the nature and cause of the accusation that the Court has consistently found as particularly important. It follows from the judgments devoted to this matter that the most satisfying would be translation of an indictment because it plays a crucial

2 See Luedicke, Belkacem and Koçv. Germany, 28 November 1978, $\$ 46$, HUDOC.

3 Ibidem, $\mathbb{} 42$.

4 Ibidem, $\mathbb{} 48$. 
role in the criminal process, in that it is from the moment of its service that the defendant is formally put on notice of the factual and legal basis of the charges against him. A defendant not familiar with the language used by the court may be at a practical disadvantage if the indictment is not translated into a language which he understands ${ }^{5}$.

Furthermore, in Kamasinski ECtHR indicated, that the right guaranteed by paragraph 3 (e) (art. 6-3e) should be practical and effective, so the obligation of the competent authorities is not limited to the appointment of an interpreter but, if they are put on notice in the particular circumstances, may also extend to a degree of subsequent control over the adequacy of the interpretation provided ${ }^{6}$. It follows from the grounds of the aforesaid judgment that the party should suggest to the court that the services of an interpreter are required or that the quality of the translation is questionable ${ }^{7}$. However, the case of Cuscani shows that this does not apply whenever there are difficulties in communicating with the defendant. In that case, the onus is on the judge to reassure himself that the absence of an interpreter would not prejudice the defendant's full involvement in a matter of crucial importance for him. For the judge is the ultimate guardian of the fairness of the proceedings and is required to treat an accused's interest with scrupulous care ${ }^{8}$.

The right to interpretation and translation is also not limited to proceedings before the court. On the contrary, in the ECtHR case law, a strong emphasis has been put on the importance of the investigation stage for the preparation of the criminal proceedings, as the evidence obtained at this stage may be decisive for the subsequent proceedings. At the same time, an individual held in police custody enjoys a certain number of rights, such as the right to remain silent or to be assisted by a lawyer. So, it is quite clear that the decision to exercise or waive such rights can only be taken if the individual concerned clearly understands the charges, so that he or she can consider what is at stake in the proceedings and assess the advisability of such a waiver. Therefore, assistance of an interpreter should be provided during the investigation stage unless it can be demonstrated in the light of the particular circumstances of the case that there are compelling reasons to restrict this right ${ }^{9}$.

5 See Hermi v. Italy, 18 October 2006, $\$ 68-70$, Protopapa v. Turkey, 24 February 2009, $\mathbb{5} 78$, HUDOC.

6 See Kamasinski v. Austria, 19 December 1989, \$74, HUDOC.

7 See also similar view expressed in Protopapa v. Turkey, 24 February 2009, \$83-86, HUDOC.

8 See Cuscani v. The United Kingdom, 24 September 2002, \$38-39, HUDOC. Similarly in Baytar $v$. Turkey, 14 October 2014, ECtHR excepted from judge to verify the skills of that interpreter, who was a member of the applicant's family waiting in the corridor ( $\$ 57)$.

9 See Saman v. Turkey, 5 April 2011, $\$ 30$, Baytar v. Turkey, 14 October 2014, $\$$ 50-53, Diallo v. Sweden (decision), 5 January 2010, \$25, HUDOC.

EuCLR Vol. 9, 2/2019 


\section{The scope of and exceptions to the right to written translation of essential documents}

After this brief introduction to the Strasbourg standard, attention should be paid to the new requirements resulting from the provisions of Directive 2010/64/EU. Significant changes relate undoubtedly to the accused's right to written translation of essential documents. As James Brannan indicates, surveys have shown that in the majority of European countries to date, very few documents have actually been systematically translated in writing, by order and at the expense of the authorities, for the benefit of a defendant in criminal proceedings. Such translation has tended to be kept to a minimum, being seen as time-consuming and costly, or quite simply unnecessary ${ }^{10}$. The Directive, however, clearly determines the separate nature of this right and goes further than the ECtHR, because the documents that need to be translated are explicitly identified: any decision depriving a person of his liberty, the charge or indictment, and the judgment ${ }^{11}$. With regard to the first category of these documents, it should be considered that the accused must be provided with both the order of application and the prolongation of pre-trial detention. In turn, the need to translate the charges refers especially to those legal systems in which a formal statement of charges in the pre-trial proceedings is a condition for conducting proceedings against a specific person and fulfils the information obligation about the subject of the proceedings. For example, in Poland this provision means an obligation to translate to the suspect the decision about presenting charges, as a result of which he becomes a party to the pre-trial proceedings and may take from this moment official procedural actions i.e. submit evidence requests and demand participation in procedural activities. It seems also quite clear that essential documents, obligatorily translated, also include any judgment. This also applies to judgments issued in various simplified procedures, in particular penalty orders imposing sanctions in relation to minor offences, which was underlined by the Court of Justice ("CJEU”) in Sleutjes".

It is all the more interesting when it comes to documents other than those mentioned explicitly in paragraph 2 . As is apparent from paragraph 3, the initiative in this area remains on the defence side, although the final decision on the translation of other documents is left to the authority conducting criminal proceedings. This final solution shows similarities to the Commission Proposal for a Council Framework Decision on certain procedural rights in criminal proceedings throughout the European Union presented in 2004. In recital 66 of this Proposal, it was pointed out that the onus should be

$10 \mathrm{~J}$. Brannan, Identifying written translation in criminal proceedings as a separate right: scope and supervision under European law, The Journal of Specialized Translation, January 2017, Issue 27, p. 44.

11 See also E. Hertog, Directive 2010/64/EU of the European Parliament and of the Council on the right to interpretation and translation in criminal proceedings: transposition strategies with regard to interpretation and translation, Monografias de Traduccione e Interpretacion 2015, issue 7, p. 85.

12 See Slentjes, CJEU judgment of 12 October 2017, C-278/16, EU:C:2017:757, \34. 
on the defence lawyer to ask for translations of any documents he considers necessary over and above what is provided by the prosecution. It was also rightly underlined that since the conduct of the defence is essentially a matter between the defendant and his lawyer, the defence lawyer is best placed to assess which documents are needed. It means, therefore, that the procedure authority should cautiously use the right to refuse to translate other essential documents requested by the defence. On the other hand, it cannot be ruled out that defence applications in this area could sometimes be aimed only to prolong proceedings. For these reasons, the Directive entrusts the final decision in this matter to the authority conducting criminal proceedings, which is obliged to safeguard the fairness of the proceedings. Obviously then, it is necessary to develop correct practices in this area.

As S. Cras and L. De Matteis observe, evidentiary material upon which the case rests are essential to safeguard the right to a fair trial ${ }^{13}$. The above-mentioned authors undoubtedly mean not the entire body of evidence gathered in the case, but the most important fragments of these materials. It goes without saying that it would be difficult to implement a postulate to translate all materials, not only because of the costs incurred, but also the time involved. Such a right would also run the risk of being abused by the accused. However, in the light of the provisions of the Directive, it should be accepted as a rule that the essential part of evidentiary materials should be translated on defence's demand. Naturally, the question arises whether there are any general rules as to which materials should be considered as such by the competent authorities. The Directive indicates that the defence's request must be reasoned.

When assessing the defence's application, the competent authority must first of all consider the scope of the evidence to be translated. The question is whether the defence's application shows that the defendant or the suspect has selected the material or if the application actually seeks to translate the majority of the case files. However, such a selection can be expected mainly from the defence counsel who has read the file and knows which materials should be translated and delivered to his client in order to enable him to defend. Secondly, in almost each case, it is not difficult to identify the most significant evidence on which the accusation is based. It seems that the protocols of testimony of the victim, eyewitnesses to the incident, co-accused, written notification of a crime, protocol from search of a suspect and protocol from inspection of the crime scene are in the foreground here.

At the request of the defence, it would also be necessary to translate the documents which are essential to ensure that the accused could be able to exercise his right to have his conviction or sentence reviewed by a higher tribunal (under Article 2 of Protocol No. 7 to the ECHR). Article 3 par. 2 of Directive 2010/64/EU explicitly indicates that "any judgment" must be translated, yet no mention is made of a written grounds of this judgment. In many legal systems, including Polish and German ones, the application for a written grounds of the judgment is a condition for appealing it. It is also obvious that without this document preparing of an appeal would be extremely difficult,

13 S. Cras, L. De Matteis, The Directive..., p. 159-160.

EuCLR Vol. 9, 2/2019 
especially if we take into consideration that, in practice, written justifications may substantially differ from the oral reasoning and are far more detailed ${ }^{14}$. Moreover, it was pointed out in the case law of the ECtHR that national courts must indicate with sufficient clarity the grounds on which they based their decision. In the case of Hadjianastassion v. Greece, the Court underlined that it is this, inter alia, which makes it possible for the accused to exercise usefully the rights of appeal available to him ${ }^{15}$. The Court referred also to this issue in Taxquet, indicating that, in proceedings conducted before professional judges, the accused's understanding of his conviction stems primarily from the reasons given in judicial decisions. In such cases, the national courts must indicate with sufficient clarity the grounds on which they base their decisions, what is clearly connected with the right to defence ${ }^{16}$. Therefore, the right of accused who does not speak the language of the court to receive a written justification should not be underestimated. This applies in particular to legal systems in which the accused can himself bring an appeal, irrespectively of his counsel's actions. In an attempt to materialise the general principle that the help of an interpreter or translator should guarantee protection of the accused against finding himself in an inferior position in comparison to the defendants who speak the language of the court, it is necessary to resolve positively his request to translate the grounds of the judgment. The issue of translation of an appeal lodged by the opposite party should be addressed in a similar way. Assuming that in the majority of domestic law systems of our cultural circle the accused has the right to refer to an appeal by the opposing party, this document should also be recognized as essential and consequently should be translated at the request of the accused.

The scope of written translation identified in the above considerations may be however limited in practice by applying exceptions included in the Article 3 paragraphs 4 and 7 of the Directive. The first of the provisions mentioned specifies that there shall be no requirement to translate passages of essential documents which are not relevant for the purposes of enabling suspected or accused persons to have knowledge of the case against them. Undoubtedly, this clause allows for a margin of appreciation as to what is important in each case ${ }^{17}$. Therefore, it would be of greater use to propose a reasonable way to interpret it. A good starting point to that end seems to be the view presented by S. Cras and L. De Matteis, who rightly point out that the provision of Article 3 (4) could prove useful in cutting down the obligation to translate voluminous documents, such as judgments involving multiple parties ${ }^{18}$. Indeed, there are no good reasons to treat this clause as a specific prerogative for authority conducting criminal proceedings to select what is more and what less important in a document already con-

14 This aspect was also discussed in Germany (see. M. Mansdörfer, C. Schmitt, Defending the Rights of Suspects and Accused Persons in Front of National Criminal Courts: Germany [in:] Effective Defence Rights in Criminal Proceedings. A European and Comparative Study on Judicial Remedies, ed. S. Allegrezza, V. Covolo, Milan 2018 p. 317).

15 Hadjianastassiou v. Greece, 16 December 1992, \$33, HUDOC.

16 Taxquet v. Belgium, 16 November 2010, \$91, HUDOC.

17 J. Brannan, Identifying written..., p. 51.

18 S. Cras, L. De Matteis, Directive..., p. 160.

\section{ARTICLES}


sidered essential. This would lead to too much interference in the way of defending. After all, the very fact that a defence request must be reasoned is a kind of restriction, in some cases even entailing an obligation to reveal preliminary direction of defence. This leads to the conclusion that the wording "not relevant" used in paragraph 4 must be interpreted restrictively, by accepting that this provision can be applied only to avoid translation of passages that do not concern the accused at all, especially fragments which concern exclusively other defendants or fragments with absolutely no connection with a particular case.

As an exception to the general rules established in Article 3, paragraph 7, provides the possibility of providing an oral translation or oral summary of essential documents instead of a written translation. And there is only one condition - such oral translation or oral summary cannot prejudice the fairness of the proceedings. Also, this clause should be interpreted restrictively and applied only in very specific circumstances ${ }^{19}$. Oral translation or summary certainly results in faster processing and lower costs; however, it may not be treated as an equivalent measure in every situation. The use of these exceptions will be justified particularly in uncomplicated cases. According to Article 6 paragraph 3 (b), everyone charged with a criminal offence has the right to have adequate time and facilities for the preparation of his defence. Oral translation or summary may affect both of the rights mentioned above. An accused should have the right to read the evidence of the accusation in peace and to rethink his line of defence. Oral translation or summary replacing translation of essential documents results in the fact that an accused cannot analyse the materials in peace, but is forced to remember orally translated information. In cases of some complexity, oral information may fade or distort in a memory of an accused, who has the right to defend himself despite actions taken by his counsel. In such cases, the exception in question should not be used too often.

\section{Translation of procedural applications submitted by the accused himself}

Another interesting issue related to the above considerations is the problem of translation of all procedural applications submitted by the accused himself in a language other than the language of the court. In Covaci, the CJEU rightly concluded that Directive 2010/64/EU does not require Member States to take responsibility for the translation of every appeal brought by the persons concerned against a judicial decision which is addressed to them, because it would go beyond the objectives pursued by the Directive itself ${ }^{20}$. However, not entirely convincing is the second thesis expressed in Covaci, according to which the right to translation provided for in Article 3(1) and (2) of Directive 2010/64 does not include, in principle, a written translation into the language of the proceedings of a document such as an objection lodged against a penalty order drawn up by the person concerned in a language of which he has a command, but

19 See J. Brannan, Identifying written..., p. 51.

20 See Covaci, CJEU judgment from 15 October 2015, C-216/14, EU:C:2015:686, $\$ 38$.

EuCLR Vol. 9, 2/2019 
which is not the language of the proceedings ${ }^{21}$. The above view is substantiated by the argument that Article 3 of the Directive concerns, in principle, only the written translation of certain documents drawn up in the language of the proceedings by the competent authorities into the language understood by the person concerned. CJEU also indicated that interpretation provided is confirmed, first, by the list of documents which Article 3(2) considers to be essential and for which a translation is therefore necessary; second, by the fact that the purpose of the right to translation provided for in Article 3 of that directive, as is apparent from paragraph 4 of that article, is to '[enable] suspected or accused persons to have knowledge of the case against them'.

Referring to the above arguments, several points should be noted. Firstly, it is incorrect to conclude that the right to translation only pertains to documents drawn up by the competent authorities. Just as in the case of the right to interpretation, it would not be possible to limit that right to interpreting only the statements of the authorities; also, the right to translation cannot be subject to such restrictions. It is also erroneous to justify that view by referring to the documents listed in Article 3 paragraph 2 because this provision contains an open catalogue of documents, of which the most important ones are explicitly mentioned. But even more flawed is a reference to the provisions of Article 3 paragraph 4, which is an exception whose permissible and limited application has already been described in considerations above. CJEU should not derive the main objectives of the right to translation from the exceptional provision of limited use. The main objectives of the Directive comprise not only information purposes ("to have knowledge of the case against them"), but first of all defence purposes, aimed at allowing the accused persons "fully to exercise their right of defence and safeguarding the fairness of the proceedings". Thus, it should be assumed that the right to translation provided by the Directive should be effective and the accused should not be deprived of the possibility of acting personally in his own defence. There is also no convincing argument that the solution for the accused is to use the assistance of a lawyer. This issue and the right to translation discussed should be treated as entirely separate ones. However, in Covaci, the Court held that in this particular situation the Directive guarantees that the accused can obtain the free assistance of an interpreter, if that person himself orally lodges an objection against the penalty order of which he is the subject at the registry of the competent national court, so that that registry records that objection, or, if that person lodges an objection in writing, can obtain the assistance of legal counsel, who will take responsibility for the drafting of the appropriate document, in the language of the proceedings. This, however, in those particular circumstances, leads to a paradox - if the accused travelled several hundred kilometres and lodged an oral statement, then he would receive the help of an interpreter, but if he sent even a very short letter (which is the simplest solution), the help of a translator would become very problematic. This shows that the interpretation provided by the CJEU in this particular case makes the translation right completely ineffective from the perspective of an accused.

\section{Ibidem, $\$ 47$.}


Of course, the above criticism of the ruling in the Covaci case should not be equated with the request for the translation of all the accused's pleadings. The foregoing considerations only indicate, in my opinion, that the accused's written requests, appeals, letters should be translated whenever it is necessary to allow him fully to exercise his right of defence. In particular, there is no need to translate accused's letters in which he presents his view of relevant facts in the case, if he can present it orally at the trial. But if domestic law provides certain defence rights, the provisions of Directive 2010/64/UE are clearly intended to safeguard the effective use of these rights. It follows that in a situation where certain procedural rights can be exercised only or mainly in a written form, then a document lodged by accused should be considered as "essential” within the meaning of Article 3 paragraph 3, in particular as regards an appeal and objections against a penal order.

\section{Translation of contacts between the lawyer and the accused}

From the perspective of effectiveness of the right to defence, the ideal solution for the accused who does not speak or understand the language of the criminal proceedings is to appoint a lawyer who could easily communicate with him. However, this is a rather rare situation and it should be noted that the issue of communication between an accused and his lawyer has not been distinctly determined in ECtHR case law. Only wording used in $\$ 74$ of Kamasinski to the effect that Article 6 (3-e) extended beyond the trial hearing to all statements which it is necessary for him to understand in order to have fair trail, could be regarded as including communication between an accused and his lawyer in a legal aid case ${ }^{22}$.

Directive 2010/64/EU introduced this right expressly in Article 2 paragraph 2. According to that regulation, whenever it is necessary for the purpose of safeguarding the fairness of the proceedings, interpretation is available for communication between the accused and his legal counsel in direct connection with any questioning or hearing during the proceedings or with the lodging of an appeal or other procedural applications such as an application for bail, as explained in Recital 20. S. Cras and L. De Matteis observed, that various studies have shown a dramatic divergence among Member States in the legal and practical implementation of the right to interpretation, especially on the ground of client-lawyer communication ${ }^{23}$. For example, the Polish Code of Criminal Procedure provides for a presence of an interpreter during the contacts between the counsel and the accused, but there are no regulations in CCP requiring the interpreter to maintain secrecy of all the facts that he will learn about during this meeting.

The natural consequence of translation of contacts between the lawyer and the accused is the necessity of securing the defence confidentiality. There is no doubt that a translator should be legally bound by a defence secrecy, in aim to exclude both the

22 D. J. Harris, M. O'Boyle, C. Warbrick, Law of the European Convention on Human Rights, London, Dublin, Edinburgh 1995, p. 271.

23 S. Cras, L. De Matteis, The Directive..., p. 158.

EuCLR Vol. 9, 2/2019 
possibility of being subject to hearing as a witness and the chance of using the information obtained from him by the authority conducting criminal proceedings. Lack of appropriate regulations in national law safeguarding confidentiality of client-lawyer communication may infringe the right of the accused to an effective exercise of his defence rights. In Brennan and S. vs. Switzerland, the ECtHR underlined the importance to be attached to the confidentiality of such consultations, emphasising that if a lawyer was unable to confer with his client and receive confidential instructions from him without surveillance, his assistance would lose much of its usefulness, whereas the Convention is intended to guarantee rights that are practical and effective ${ }^{24}$. Therefore, it seems that a universal solution in all Member States should be an exclusionary rule (or any equivalent measure) that eliminates the possibility of interrogating an interpreter. Furthermore, increasing the trust between an interpreter and accused would be to allow the defence to indicate the person of interpreter. It follows that, in a matter of fact, the interpreter should be primarily the assistant to the accused himself, not the assistant to the authorities conducting criminal proceedings.

\section{Quality of interpretation and translation}

Another important issue is connected with the professional qualifications of interpreters and translators working in criminal cases. Both interpretation and translation provided under Directive 2010/64/EU shall be of a quality sufficient to safeguard the fairness of the proceedings, in particular by ensuring that suspected or accused persons have knowledge of the case against them and are able to exercise their right of defence. The Directive sets no criteria for the qualifications of translators or interpreters - this is left to national law 25 .

Unfortunately, also in this field there is still much to be done. As L. Katschinka indicates, in most of EU Member States, recruitment and/or appointment is only on adhoc basis in line with the specific needs of a given case. In practice, it means that "the next best person" is often called into the police station to help with communication which may lead to mistakes during investigative procedures caused by interpreting services, and subsequently to delays or miscarriage of justice ${ }^{26}$. In a similar vein, E. Her-

24 See S. vs Switzerland, 28 November 1991, $\ 48$, Brennan vs. The United Kingdom, 16 Octo-

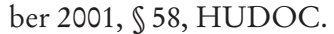

25 L. Siry, The ABC of the Interpretation and Translation Directive [in:] Effective..., ed. S. Allegrezza, V. Covolo, p. 50.

26 L. Katschinka, The impact of Directive 2010/64/EU on the right to interpretation and translation in criminal proceedings [in:] Traduzione e interpretazione per la societa e le istituzioni, ed. C. Falbo, M. Viezzi, Trieste 2014, p. 108-110. In Poland, in practice, prosecutor office mainly uses sworn translators, who rather give a guarantee of interpretation of sufficient quality. However, relevant art. 204 of Polish CCP does not set any specific conditions for the person of interpreter or translator. Therefore, it can be both a sworn translator and an ad hoc translator. It should be also noted that some legal systems provide even more controversial solutions in practice. For example in Belgium in exceptional circumstances it is even possible to move on with the proceedings if all reasonable efforts have been exhausted to find an ap- 
tog points out that no one would put their trust in the hands of a defence counsel dragged in from the street or submit to an interview by an "ad hoc" police officer. Therefore, an interpreter shall be properly trained to ensure quality of translation delivered $^{27}$. On the other hand, such a need is also felt by interpreters called to participate in procedural activities. For example, Polish researchers indicate that although finding an interpreter for a hearing is uneasy, interpreters are reluctant to work in courts for the following reasons: they do not feel competent enough in the field of legal interpretation, they are afraid of responsibility related to court interpretation and, last but not least, their pay is too $\operatorname{low}^{28}$. The state of affairs described above departs from the requirements of Directive 2010/64/UE, which states in Article 5 paragraph 2 that Member States shall endeavour to establish a register or registers of independent translators and interpreters who are appropriately qualified and - as follows from Recital 31 - the most desirable solution is to use the services of only qualified legal translators and interpreters in the proceedings. It appears that this may lead to a smaller number of interpreters available to authorities conducting criminal proceedings, but their participation in activities could be conducted via videoconferences. Besides, it also seems necessary to record all procedural activities during which interpretation is carried out (naturally except for contacts between the accused and his counsel). While in the case of translation it is possible to later verify its quality, in the case of interpretation, it is possible only by recording. This problem has already been noticed during the work on the Proposal for the Council Framework Decision on certain procedural rights in criminal proceedings throughout the European Union. Article 9 of the Proposal provided that, in case of an application to the ECtHR on the grounds that the interpretation was inadequate and damaging to applicant's effective participation in the proceedings, it is important to have a method of verification of the interpretation put in place. It is therefore incumbent on Member States to ensure that a recording exists in the event of a dispute ${ }^{29}$. The Directive does not impose obligation of video recording in this respect on Member States; however, it implicitly follows from Article 7 that this would be the only effective measure in case of a dispute over the quality of interpretation.

$* * *$

The foregoing considerations indicate that despite the passage of time, proper implementation of the standard provided for in Directive 2010/64/EU still causes consider-

propriate, qualified interpreter and have nonetheless failed (see M. Panzavolta, Defending the Rights of Suspects and Accused Persons in Front of National Criminal Courts: Belgium [in:] Effective..., ed. S. Allegrezza, V. Covolo, p. 236).

27 See E. Hertog, Directive..., p. 92.

28 See K. Nartowska, Court interpreting in Poland in the light of Directive 2010/64/EU. The stage of the art and challenges for the future [in:] Przysz tos' zawodu tumacza przysieg lego $i$ specjalistycznego - wspótczesne wyzwania, ed. M. Czyżewska, A. Matulewska, Warsaw 2016, p. 36-38.

29 https://eur-lex.europa.eu/legal-content/PL/TXT/PDF/?uri=CELEX:52004PC0328\&from= EN. See also E. Hertog, Directive..., p. 80. 
able difficulties. And, as shown above, glaring discrepancies among Member States in the legal and practical implementation of the right to interpretation and translation may result in divergent procedural standard in individual cases, depending on the location of the criminal proceedings.

\title{
Can Cases of Persecution Based on Gender Identity Be Tried by the ICC?
}

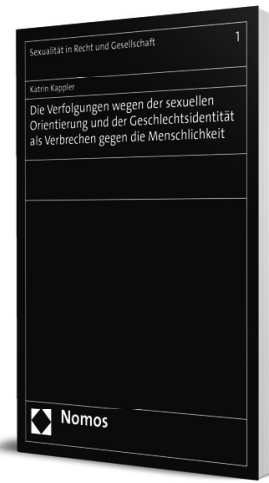

\author{
Die Verfolgungen wegen der sexuellen \\ Orientierung und der Geschlechts- \\ identität als Verbrechen gegen die \\ Menschlichkeit \\ By Dr. Katrin Kappler \\ 2019, 382 pp., pb., € 100.00 \\ ISBN 978-3-8487-5921-7 \\ (Sexualität in Recht und Gesellschaft, vol. 1) \\ nomos-shop.de/41779 \\ In German language
}

In this book, Katrin Kappler analyses the definition of gender in the Rome Statute and shows that sexual orientation and gender identity are not included in Art. 7 (3) although the rights to sexual orientation and gender identity are human rights. This finding allows her to propose certain improvements.

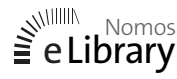

To order please visit www.nomos-shop.de,

send a fax to (+49) 7221/2104-43 or contact your local bookstore.

Returns are at the addressee's risk and expense.

Nomos 